Research Article

\title{
The Effects of Prior Outcomes on Risky Choice: Evidence from the Stock Market
}

\author{
Fenghua Wen, Xu Gong, Youcong Chao, and Xiaohong Chen \\ School of Business, Central South University, Changsha, Hunan 410083, China \\ Correspondence should be addressed to Xiaohong Chen; csu_cxh@163.com
}

Received 26 December 2013; Revised 2 March 2014; Accepted 2 March 2014; Published 31 March 2014

Academic Editor: Chuangxia Huang

Copyright (C) 2014 Fenghua Wen et al. This is an open access article distributed under the Creative Commons Attribution License, which permits unrestricted use, distribution, and reproduction in any medium, provided the original work is properly cited.

\begin{abstract}
How do prior outcomes affect the risk choice? Research on this can help people to understand investors' dynamic decisions in financial market. This paper puts forward a new value function. By analyzing the new value function, we find that the prior gains and losses have an impact on the form of value function and the current investors' risk attitude. Then the paper takes the behavior of the whole stock market as the research object, adopts aggregative index number of 14 representative stocks around the world as samples, and establishes a TVRA-GARCH-M model to investigate the influences of prior gains and losses on the current risk attitude. The empirical study indicates that, at the whole market level, prior gains increase people's current willingness to take risk assert; that is to say, the house money effect exists in the market, while people are more risk aversion following prior losses.
\end{abstract}

\section{Introduction}

Investing behavior under risk in financial market is a kind of dynamic decision-making behavior, and different risk attitude of investors will lead them to different risk decisionmaking. Thaler and Johnson [1], Keasey and Moon [2], Sadorsky [3], Dillenberger and Rozen [4], Duxbury et al. [5], Huang and Chan [6], and so forth have done researches and found that people's risk attitude would change with circumstances, and prior outcomes will affect the subsequent risk-taking behavior of investors.

What kind of influence does prior gains and losses exert on investors' subsequent investing behavior on earth? Thaler and Johnson [1] have done representative researches on this problem. With many experiments of money gambles, they find that people are more willing to take greater risk after they got gains; namely, they become more risk seeking, which is called "house money effect," while they are more likely to avoid risks if they got prior losses. In experimental researches designed by many other scholars [7-11], this influence has also been proved. Thaler and Johnson [1], by examining editing rules in prospect theory, gave initiatory explanations to this problem, the current potential losses can be offset by prior gains, so the investors become less "painful" and then can bear more risks, while with prior losses, further losses will make them more painful, so investors tend to avoid risks. Linville and Fischer [12], Sullivan and Kida [13], and so forth have also done researches and expressed similar viewpoints. Sullivan and Kida [13] explain this phenomenon as follows: decision makers' attention on threat will induce their risk aversion actions, while their attention on opportunities will induce risky actions.

On the basis of prospect theory, Barberis et al. [14] make analysis through constructing theoretical asset pricing model. They hold that prior gains will reduce the investors' sensitivity on risk, while prior losses and further losses will intensify investors' pains, thus increasing their extent of risk aversion. Barberis and Xiong [15] do researches from a new perspective on the influence of prior gains and losses on current investing behaviors. They establish a multiperiod model. In the model, investors determine their future risk choices according to the results from their prior behaviors. They find that different expected return, trading time, and the shapes of value function can affect their subsequent risk attitude. Dillenberger and Rozen [4] propose a model of history-dependent risk attitude. In the model, they take prior gains and losses as endogenous variable to analyze the influence on the investors' future risk choices. With the analysis, it can be found that prior decision-making behaviors can exert great effects on investors' risk attitude. When prior 
performance is good, risk aversion extent of decision makers decreases, and the extent of their risk aversion increases when they suffer from prior pains and frustrations.

Shefrin and Statman [16] and Odean [17] explained disposition effect from the perspective of prospect theory, but the conclusion about the influence of prior gains and losses on current risk attitude is seemingly not in accordance with disposition effect. Barberis et al. [14] point out that disposition effect is mainly about investors' different ways of disposing assets when they are confronted with gains and losses, and the gains and losses are still "unrealized," while prior gains and losses refer to the "realized" outcomes. For instance, when the current state is in losses, investors may become risk-seeking so as to stop the losses at the end of the period, which possibly leads to disposition effect. The influence of prior gains and losses on current risk attitude actually means that if investors fail in stopping the losses when the period ends and still keeps a state of losses, investors will tend to avoid risk in the following period. In this sense, the influence of prior outcomes on current risk attitude is not contradictory with the description of disposition effect. In fact, the basic influence of prior gains and losses on current risk attitude cannot be explained by initiatory value function, because the value function only describes investors' risk attitude for the current gains and losses, and it does not involve the prior gains and losses.

In aspect of the empirical researches on the influence of prior gains and losses on current risk attitude, most of the past studies are done through psychological experiments. Hirshleifer [18] emphasizes that the results from these psychological experiments are not all effective when applied to the actual financial decision-making behaviors. Therefore, some scholars try to use real data on the market to investigate influence of prior outcomes on current risk attitude. Brown et al. [19] take data of stock right registration of IPO between 1995 and 2000 in Australia stock market as samples to do empirical research, and the result shows that prior gains can offset subsequent losses and the investors become more risk seeking. Hsu and Chow [20] adopt the client database and historical deal database between January 1, 1995, and September 31, 1999, in Taiwan stock market to investigate the behaviors of individual investors on the market; the result shows that individual investors tend to purchase stocks of high standard deviation when they get prior gains; that is, they become more risk seeking, which just verifies the "house money effect." In futures market, empirical tests all adopt intraday transaction data. For professional investors, Frino et al. [21] make empirical studies on the behaviors of professional futures investors in Sydney Futures Exchange and find that the dealers also turn more risk seeking after they get gains, while their extent of risk aversion increases otherwise. Liu et al. [22] make studies on the behaviors of market makers in Taiwan futures exchange and find that gains in the morning will make the market-makers' extent of risk aversion decreases in the afternoon. Hsu and Chow [23] found that individuals tend to take greater risk when gains are more substantial. Their empirical evidence suggests that the house money effect is actually discernible in the real world financial markets and not just in artificial laboratory experiments.
It can be seen from the literature review that most of the past empirical researches on the relationship between prior outcomes and current risk attitude are done with the help of psychological experiments and data of investors' transaction accounts. On the premise of investors' limited rationalities, real market scenes can hardly be simulated through experiment, and data of investors' transaction accounts is often not representative. In addition, their sample size is not large enough. To solve this problem, this paper puts forward a new value function which explains a phenomenon about the effects of prior outcomes on risky choice. And this paper takes the behavior of the whole stock market as the research object, adopts aggregative index number of 14 representative stocks around the world as samples, and establishes a TVRAGARCH-M model to investigate the influence of prior gains and losses on current risk attitude.

The frame of this paper is as follows. Section 2 is about the value function and risk aversion level. Section 3 is an explanation about the effects of prior outcomes on risky choice. Section 4 is an empirical analysis about the effects of prior outcomes on risky choice. Finally, conclusions are given in Section 5.

\section{The Value Function and Risk Aversion Level}

In this paper, we use the value function of power function type which is proposed by Tversky and Kahneman [24]. The expression of value function is as follows:

$$
V(x)= \begin{cases}x^{\alpha}, & x \geq 0 \\ -\lambda(-x)^{\beta}, & x<0\end{cases}
$$

where $\alpha$ represents the concave or convex level of gain area in the function. $\beta$ represents the concave or convex level of loss area in the function. If $\alpha, \beta<1$, they represent diminishing sensitivity. $\lambda$ represents the steep level of loss area. If $\lambda>1$, it represents that investors have loss aversion. In addition, the value function is concave in the gain area, and it represents that investors have risk aversion in this situation. The value function is convex in the loss area, and it represents that investors have risk seeking in this station.

In order to explain the situation that the prior gains or losses have influence on the current risk attitude of investors, this paper used the risk aversion coefficient to measure investors' risk attitude. Arrow [25] and Pratt [26] put forward an absolute risk aversion coefficient. And this coefficient has been widely used by many scholars, such as [27-29]. Thus, this paper used this absolute risk aversion coefficient to measure risk attitude of investors. The expression is as follows:

$$
R=-\frac{V^{\prime \prime}(x)}{V^{\prime}(x)}
$$

where $R$ is an absolute risk aversion coefficient of Arrow-Pratt and it represents the risk compensation for the unit variance risk. If $R>0$, it represents the risk aversion. If $R=0$, it represents the risk neutral. If $R<0$, it represents the risk seeking. 


\section{The Effects of Prior Outcomes on Risky Choice: An Explanation from Prospect Theory}

In traditional value functions, calculating the gains and losses and making decisions for corresponding risk, they did not take into account the prior gains and losses states, that is to say, the current risk decision-making behavior doesn't have memory. However, Barberis et al. (BHS) [14] argued that the prior gains or losses have great impact on the investors' current risk attitude, and the impact cannot expressed by the prospect theory.

We suppose that $S_{t}$ represents the price of risk assets at $t$ and $R_{t+1}$ represents the return rate of risk assets at $t+1$. Therefore, $S_{t} R_{t+1}=S_{t+1}$, and the gains and losses at $t+1$ are $X_{t+1}=S_{t+1}-S_{t}=S_{t} R_{t+1}-S_{t}$.

The traditional value function did not take into account the prior gains and losses states; that is to say, they argued that the investors are "no memory" when they make decision. In order to take into account the prior gains and losses, we introduce the "Benchmark Level." Here, $Z_{t}$ represents the "Benchmark Level," and $S_{t}-Z_{t}$ represent the individual measures of investors' gains and losses at the previous period. In this paper, we only take into account the relative relationship between $Z_{t}$ and $S_{t}$, so we define $z_{t}=Z_{t} / S_{t} . z_{t}<1$ represent the prior gains, and $z_{t}>1$ represent the prior losses.

3.1. Case of Prior Gains. If the investors lose $R_{t+1}-1$ (namely, $0<z_{t} \leq 1$ ) and they do not take into account the prior gains, the investors will suffer from the "pain" $\lambda$. According to the viewpoint of BHS, if the investors take into account the prior gains, they will put the loss of $R_{t+1}-1$ into two parts. A part of losses are offset by the prior gains, which reduce the pain which was brought the current losses. However, the part of losses which are not offset by the prior gains do not change. Therefore, taking into account the prior gains, we get the value function as follows:

$$
\begin{aligned}
& V\left(R_{t+1}, z_{t}\right) \\
& \quad= \begin{cases}\left(R_{t+1}-1\right)^{\alpha}, & R_{t+1} \geq 1 \\
-\left[-\left(R_{t+1}-1\right)\right]^{\beta}, & z_{t} \leq R_{t+1}<1 \\
-\left[-\left(z_{t}-1\right)\right]^{\beta}-\lambda\left[-\left(R_{t+1}-z_{t}\right)\right]^{\beta}, & R_{t+1}<z_{t} .\end{cases}
\end{aligned}
$$

According to the "house money effect," if $1>R_{t+1} \geq z_{t}$, the current losses will be completely offset by the prior gains and $V\left(R_{t+1}, z_{t}\right)=-\left[-\left(R_{t+1}-1\right)\right]^{\beta}$ in this case. If $1 \geq z_{t}>$ $R_{t+1}$, a part of losses $z_{t}-1$ will be completely offset by the prior gains and the other part of losses $R_{t+1}-z_{t}$ cannot be offset by the prior gains. In this case, $V\left(R_{t+1}, z_{t}\right)=-\left[-\left(z_{t}-1\right)\right]^{\beta}-$ $\lambda\left[-\left(R_{t+1}-z_{t}\right)\right]^{\beta}$. These above cases can be shown in Figure 1.

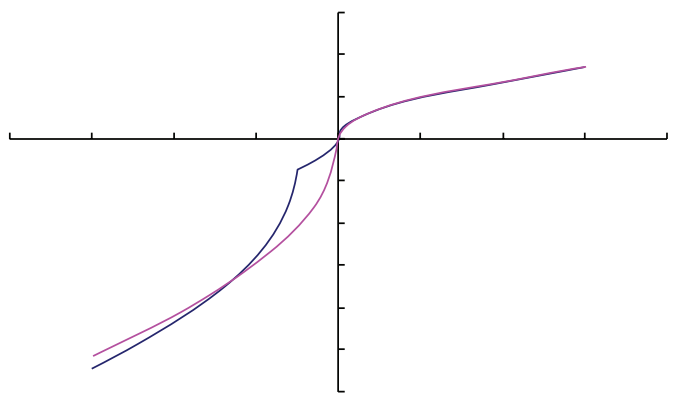

FIGURE 1: Utility of gains and losses in the presence of prior gains.

In order to facilitate the discussion of risk attitude, we suppose that $x=R_{t+1}-1$ and $x_{0}=z_{t}-1$. So the value function can be simplified as follows:

$$
V(x)= \begin{cases}x^{\alpha}, & x \geq 0 \\ -[-x]^{\beta}, & x_{0} \leq x<0 \\ -\left[-x_{0}\right]^{\beta}-\lambda\left[-\left(x-x_{0}\right)\right]^{\beta}, & x<x_{0} .\end{cases}
$$

In fact, if the prior gains were 0 , the expression of value function will be as follows:

$$
V(x)= \begin{cases}x^{\alpha}, & x \geq 0 \\ -\lambda(-x)^{\beta}, & x<0\end{cases}
$$

By calculating the risk aversion coefficients at $x \geq 0$ and $x_{0} \leq x<0$, we can find that the prior gains do not have influence on the current risk attitude.

We analyze the risk attitude at $x<x_{0}$. When the prior gains were 0 , we can calculate the risk aversion coefficients as follows:

$$
R=-\frac{V^{\prime \prime}(x)}{V^{\prime}(x)}=-\frac{-\lambda \beta(\beta-1)(-x)^{\beta-2}}{\lambda \beta(-x)^{\beta-1}}=\frac{1-\beta}{x} .
$$

Similarly, when the investors got the gains, $V(x)=$ $-\left[-x_{0}\right]^{\beta}-\lambda\left[-\left(x-x_{0}\right)\right]^{\beta}$ and $-V^{\prime \prime}(x) / V^{\prime}(x)=(1-\beta) /(x-$ $\left.x_{0}\right)<(1-\beta) / x$.

Therefore, if $x<x_{0}$, the risk compensation becomes smaller and the risk aversion level becomes lower when the investors got the gains.

All in all, the prior gains have impact on the current value function, so the current risk aversion level becomes low. However, when the investors have different gains and losses in the current period, the investors' risk attitude still accords with the basic feature of value function.

3.2. Case of Prior Losses. If the investors had the losses in the previous period (namely, $z_{t}>1$ ), further losses will bring the investors greater "pain." In contrary, the current gains can induce a part of pain of the prior losses. According to the viewpoint of BHS, if the investors take into account the prior losses, they will put the gains of $R_{t+1}-1$ into two parts. A part of gains are offset by the prior losses, which reduce 


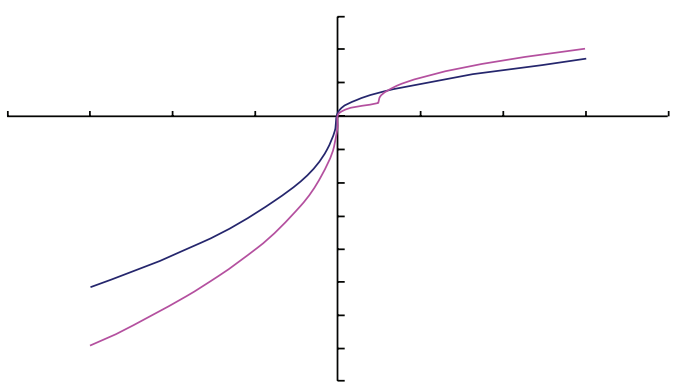

FIGURE 2: Utility of gains and losses in the presence of prior losses.

the joy which was brought the current gains. However, the part of gains which are not offset by the prior losses do not change. Therefore, taking into account the prior losses, we get the value function as follows:

$$
\begin{aligned}
& V\left(R_{t+1}, z_{t}\right) \\
& \quad= \begin{cases}\left(R_{t+1}-z_{t}\right)^{\alpha}+\eta\left(z_{t}-1\right)^{\alpha}, & R_{t+1} \geq z_{t} \\
\eta\left(R_{t+1}-1\right)^{\alpha}, & z_{t}>R_{t+1} \geq 1 \\
-\lambda\left(z_{t}\right)\left[-\left(R_{t+1}-1\right)\right]^{\beta}, & R_{t+1}<1,\end{cases}
\end{aligned}
$$

where $0<\eta<1$ represents a utility degree coefficient.

In order to facilitate the discussion of risk attitude, we suppose that $x=R_{t+1}-1$ and $x_{0}=z_{t}-1$. So the value function can be simplified as follows:

$$
V(x)= \begin{cases}\left(x-x_{0}\right)^{\alpha}+\eta x_{0}^{\alpha}, & x \geq x_{0} \\ \eta x^{\alpha}, & x_{0}>x \geq 0 \\ -\lambda\left(x_{0}\right)[-x]^{\beta}, & x<0 .\end{cases}
$$

If the prior gains are 0 , the expression of value function will be as follows:

$$
V(x)= \begin{cases}x^{\alpha}, & x \geq 0 \\ -\lambda(-x)^{\beta}, & x<0 .\end{cases}
$$

These above cases can be shown in Figure 2.

By calculating the risk aversion coefficients at $x \leq x_{0}$, we can find that the prior losses do not have influence on the current risk attitude.

We analysis the risk attitude at $x>x_{0}$. When the prior gains were 0 , we can calculate the risk aversion coefficients as follows:

$$
R=-\frac{V^{\prime \prime}(x)}{V^{\prime}(x)}=-\frac{\alpha(\alpha-1) x^{\alpha-2}}{\alpha x^{\alpha-1}}=\frac{1-\alpha}{x} .
$$

Similarly, when the investors got the gains, $V(x)=$ $\left(x-x_{0}\right)^{\alpha}+\eta x_{0}^{\alpha}$ and $R^{\prime}=-V^{\prime \prime}(x) / V^{\prime}(x)=(1-\alpha) /\left(x-x_{0}\right)>$ $(1-\alpha) / x$.

Therefore, if $x<x_{0}$, the risk compensation becomes bigger and the risk aversion level becomes higher when the investors got the losses.

In one word, the prior losses have impact on the current value function, and the current risk aversion level becomes higher. However, when the investors have different gains and losses in the current period, the investors' risk attitude still accords with the basic feature of value function.

According to the above analysis, we can find that the investors become more risk seeking when they got the gains in the previous period ("house money effect" [1]); the investors become more risk aversion when they got the losses in the previous period.

\section{The Effects of Prior Outcomes on Risky Choice: Empirical Analysis}

4.1. The Thoughts of Empirical Analysis. To study the influence of prior gains and losses on current risk attitude, it is a must to measure the prior gains and losses and make a proper description on the change of investors' risk attitude.

For the measuring of prior gains and losses, the prospect theory put forward by Kahneman and Tversky [30] emphasizes that investors' judgments of gains and losses are based on the reference point; namely, the part higher than the point is regarded as gains, and losses otherwise. Therefore, the choice of proper reference point is a critical factor in defining gains and losses.

Reference point is a subjective psychological criterion for evaluation, and there is no normative and definite unified criterion. Though in many studies the status quo is chosen as the reference point, Tversky and Kahneman [31] recognize that "there are other situations in which gains and losses are coded relative to an expectation or aspiration level that differs from the status quo" [22]. In recent years, many studies find that reference point as defined by people's expectations (e.g., $[32,33]$ ). Köszegi and Rabin (short for KR, [34-36]) think that existing researches that have taken status quo as reference point can all understand like the following in essence: people hope to keep the status quo and so to take status quo as reference point is the same as those who take expectation directly as reference point. They put forward reference pointdependent model and recognize that when measuring gains and losses, rational expectation based on recent information is better than taking status quo as reference point. At this time, unexpected gains (losses) can be seen as gains (losses).

This paper adopts KR's viewpoint and chooses investors' rational expectations of gains based on prior information as reference point. For instance, for securities $i$, supposing that the return is $r_{t i}(t=1,2, \ldots, T)$, if investors' expected return $E\left(r_{t i}\right)$ is based on information of period $t-1$, the investor's reference point in period $t$ is $E\left(r_{t i}\right)$. According to prospect theory, the investor's gains and losses in period $t$ can be expressed as $r_{t i}-E\left(r_{t i}\right)$, which will be called unexpected gains and losses in this paper.

For the measuring of investors' risk attitude, Arrow [25] and Pratt [26] propose an absolute risk aversion coefficient, it is the most representative and has already been widely applied (such as [27, 28, 37]). The coefficient denotes the average risk compensation that the investors require for each unit of variance risk, the larger the number is, the more the risk compensation demanded is, so that the investors are more risk aversion; otherwise the risk compensation is less and the 
extent of risk aversion is lesser. Wen and Yang [38] recognize that the risk compensation coefficient $\gamma$ in GARCH-M model, which is in accordance with Arrow-Pratt's absolute risk aversion coefficient, and it can be used to describe the investors' risk attitude on the market. However, in traditional GARCH-M model, a hypothesis is actually implied: in a certain period, the risk compensation the investor demands for each unit of risk is fixed. However, [39-41] find that people's risk attitude is changing with time. The greater the extent of risk aversion is, the more the compensation return the investor demands for each unit of risk. This means that the risk compensation coefficient also changes with factors like time, and so forth. From the literature review above, prior gains and losses are an important reason for inducing investors' time-varying risk attitude. Therefore, this paper introduces time-varying risk compensation coefficient into traditional GARCH-M model to illustrate the influence of prior gains and losses on investors' risk attitude.

Combined with empirical thinking analysis, this paper chooses traditional GARCH-M model as basic model. There are mainly two reasons. First, in GARCH-M model, securities return can be seen as formed by expected and unexpected return, and the extracted residual sequence is just the unexpected return. On financial market, the distribution of securities return is usually characterized by leptokurtic and heavytailed nonnormal distribution and heteroscedastic volatility in return series, while GARCH-M model can remove these distribution features of return rate; in this way, the extracted residual series is just the "real" unexpected return that is not influenced by investors' behavioral bias. Second, this paper mainly studies the influence of prior unexpected gains and losses on current risk attitude. In GARCH-M model, as securities return contains risk compensation, that is, gains and risk are closely correlated, and conditional variance of return rate is a proper indicator in measuring risk, therefore, GARCH-M model is suitable in investigating the relationships between prior unexpected gains and investors' risk attitude on the market.

Therefore, we take traditional GARCH-M model as basic model, introduce time-varying risk compensation coefficient which can reflect the change of investors' risk attitude, establish a new model, and take residual sequence extracted from the new model as the representative variable of unexpected gains and losses, so as to make empirical studies on the relationship between prior unexpected outcomes and investors' current risk attitude on a market level.

4.2. Model for Empirical Analysis. The expression of traditional GARCH-M model is as follows:

$$
\begin{aligned}
& r_{t}=c+x_{t} \beta+\gamma h_{t}+\varepsilon_{t}, \\
& \varepsilon_{t}=\sqrt{h_{t}} \cdot v_{t}, \\
& h_{t}=\alpha_{0}+\sum_{i=1}^{q} \alpha_{i} \varepsilon_{t-i}^{2}+\sum_{j=1}^{p} \theta_{j} h_{t-j} .
\end{aligned}
$$

Here, $v_{t}$ is i.i.d., $E\left(v_{t}\right)=0, D\left(v_{t}\right)=1$, and $\sum_{i=1}^{q} \alpha_{i}+\sum_{j=1}^{p} \theta_{j}<1$.
In this model, return rate is decomposed into three parts: the average return rate $c+x_{t} \beta$ that is relevant to exogenous variables, return rate $\gamma h_{t}$ that is based on risk compensation, and volatility return rate which is subject to external impact, $\varepsilon_{t}$. Besides, from mean equation, the expectations based on information in period $t-1$ can be directly obtained: $E\left(r_{t}\right)=$ $c+x_{t} \beta+\gamma h_{t}$. It can be seen the following.

(1) Combined with the above analysis, taking the expected return level $E\left(r_{t}\right)$ as reference point, the unexpected gains and losses are $\varepsilon_{t}=r_{t}-E\left(r_{t}\right)$, which embodies the gains and losses in period $t$.

(2) $\gamma=\Delta r_{t} / \Delta h_{t}, \gamma$ is the risk compensation the investor demands for each unit of variance risk, which is called risk compensation coefficient. So $\gamma$ can be used to measure magnitude of risk compensation that an investor assumes. The larger $\gamma$ is, the greater the extent of risk aversion of the whole market is; otherwise the extent of risk aversion of the whole market is lesser.

Therefore, to examine the influence of prior unexpected gains and losses on current risk attitude, combined with former theoretical analysis, we suppose that there exists simple linear relationship between them and establish a timevarying risk attitude GARCH-M model, namely, TVRAGARCH-M. The details of the model are as follows:

$$
\begin{aligned}
r_{t} & =c+x_{t} \beta+\gamma_{t} h_{t}+\varepsilon_{t}, \\
\gamma_{t} & =\eta_{0}+\eta_{1} \varepsilon_{t-1}, \\
\varepsilon_{t} & =\sqrt{h_{t}} \cdot v_{t}, \\
h_{t} & =\alpha_{0}+\sum_{i=1}^{q} \alpha_{i} \varepsilon_{t-i}^{2}+\sum_{j=1}^{p} \theta_{j} h_{t-j} .
\end{aligned}
$$

Here, risk compensation coefficient is no longer fixed but change with time because of the influence of prior unexpected outcomes. In the model, $\varepsilon_{t-1}$ stands for prior unexpected gains and losses, $\eta_{0}$ stands for the fixed risk compensation demanded for each unit of variance risk, and $\eta_{1}$ illustrates the influence of prior unexpected gains and losses on current risk compensation coefficient. If the general conclusion in the former literature on the relationship between prior outcomes and current risk attitude is right, $\eta_{1}$ should significantly be less than zero. If $\varepsilon_{t-1}>0$, it means that the prior gains will reduce current risk compensation coefficient; namely, the extent of risk aversion decreases; in this way, the empirical experiment verifies the "house money effect." If $\varepsilon_{t-1}<0$, it means that prior losses will increase current risk compensation coefficient and the extent of risk aversion increases.

4.3. Result of Empirical Research. According to the IMF (International Monetary Fund) report in 2010, the countries whose GDP rank among the top ten in 2009 in turn are America, Japan, China, German, France, UK, Italy, Brazil, Spain, and Canada, and the total amount of their GDP amounts to more than $50 \%$ of the world GDP. Meanwhile, according to report of WFE (World Federation Of Exchanges), the 
TABLE 1: Basic statistics for daily return series of composite indexes.

\begin{tabular}{|c|c|c|c|c|c|c|}
\hline & Mean & Std. Dev & Skewness & Jarque-Bera & ADF test & ARCH-LM test \\
\hline S\&P 500 & -0.006210 & 1.400254 & -0.114384 & 6587.713 & -38.3026 & 153.6778 \\
\hline Dowjones & -0.000915 & 1.317075 & 0.047682 & 6299.268 & -37.8115 & 150.5500 \\
\hline NASDAQ & -0.000440 & 1.747697 & 0.175155 & 2298.068 & -37.5163 & 100.7235 \\
\hline NYSE & 0.002528 & 1.397271 & -0.283905 & 9121.484 & -37.44753 & 190.2067 \\
\hline Nikkei225 & -0.011831 & 1.660565 & -0.292542 & 3821.667 & -48.86196 & 325.9931 \\
\hline FTSE100 & -0.005793 & 1.357928 & -0.106906 & 3927.123 & -21.9967 & 153.3013 \\
\hline SSE & 0.019730 & 1.714406 & -0.105263 & 1629.944 & -27.6192 & 5.505159 \\
\hline DAX & -0.002373 & 1.692539 & 0.070301 & 1798.858 & -49.73979 & 119.7851 \\
\hline CAC 40 & -0.016852 & 1.587710 & 0.052661 & 2746.579 & -23.62872 & 111.7417 \\
\hline GSPTSE & 0.012089 & 1.258705 & -0.678169 & 8860.508 & -50.73949 & 157.5477 \\
\hline MIBTEL & -0.030404 & 1.316993 & -0.158677 & 4999.875 & -20.68796 & 123.2172 \\
\hline SMSI & 0.020879 & 1.364191 & -0.061860 & 4384.783 & -46.61378 & 123.3914 \\
\hline BVSP & 0.067122 & 2.025965 & -0.093354 & 1355.060 & -46.66775 & 131.7443 \\
\hline Hangseng & 0.017219 & 1.676433 & 0.037793 & 7002.364 & -48.77268 & 223.4757 \\
\hline
\end{tabular}

Note. J-B statistic in the table and the result of both the ADF test and ARCH-LM test are significant at significance level of $1 \%$.

TABLE 2: Model estimated results.

\begin{tabular}{|c|c|c|c|c|c|c|c|}
\hline Parameter & S\&P 500 & Dow J & Nasdaq & NYSE & N 225 & FTSE 100 & SSE \\
\hline$\eta_{0}$ & $\begin{array}{l}0.016935 \\
(0.1604)\end{array}$ & $\begin{array}{c}0.024478 \\
(0.0633)\end{array}$ & $\begin{array}{l}0.017819 \\
(0.1063)\end{array}$ & $\begin{array}{c}0.019799 \\
(0.0011)\end{array}$ & $\begin{array}{l}0.014883 \\
(0.2088)\end{array}$ & $\begin{array}{c}0.025348 \\
(0.0572)\end{array}$ & $\begin{array}{l}0.020078 \\
(0.0449)\end{array}$ \\
\hline$\eta_{1}$ & $\begin{array}{c}-0.020366 \\
(0.0000)\end{array}$ & $\begin{array}{c}-0.022310 \\
(0.0000)\end{array}$ & $\begin{array}{c}-0.007665 \\
(0.1198)\end{array}$ & $\begin{array}{c}-0.014030 \\
(0.0011)\end{array}$ & $\begin{array}{c}-0.006797 \\
(0.0728)\end{array}$ & $\begin{array}{c}-0.017668 \\
(0.0029)\end{array}$ & $\begin{array}{c}-0.002806 \\
(0.5451)\end{array}$ \\
\hline Log likelihood & -3345.516 & -3247.181 & -3995.514 & -3275.370 & -3890.007 & -3311.171 & -4086.738 \\
\hline Parameter & DAX & CAC 40 & GSPTSE & MIBTEL & SMSI & BVSP & Hangseng \\
\hline$\eta_{0}$ & $\begin{array}{c}0.027183 \\
(0.0162)\end{array}$ & $\begin{array}{l}0.021502 \\
(0.0648)\end{array}$ & $\begin{array}{c}0.023915 \\
(0.1318)\end{array}$ & $\begin{array}{c}0.025959 \\
(0.1112)\end{array}$ & $\begin{array}{l}0.041783 \\
(0.0074)\end{array}$ & $\begin{array}{c}0.033652 \\
(0.0018)\end{array}$ & $\begin{array}{c}0.026084 \\
(0.0371)\end{array}$ \\
\hline$\eta_{1}$ & $\begin{array}{c}-0.009019 \\
(0.0494)\end{array}$ & $\begin{array}{c}-0.011875 \\
(0.0139)\end{array}$ & $\begin{array}{c}-0.012657 \\
(0.0390)\end{array}$ & $\begin{array}{c}-0.005938 \\
(0.3663)\end{array}$ & $\begin{array}{c}-0.003250 \\
(0.5811)\end{array}$ & $\begin{array}{c}0.000205 \\
(0.9522)\end{array}$ & $\begin{array}{c}-0.004030 \\
(0.2297)\end{array}$ \\
\hline Log likelihood & -3939.775 & -3801.570 & -3139.693 & -3088.955 & -3033.973 & -4511.389 & -3817.039 \\
\hline
\end{tabular}

Note. In this paper, we choose normal distribution, $t$ distribution, and GED distribution as residual distribution assumption to conduct the estimation, and the results are basically the same. As the space is limited, only the estimated result in the hypothesis of normal distribution is shown here.

market value of most of stock markets in these countries is more than a thousand billion US dollars by 2009. To ensure the representative quality of the data, this paper chooses representative stock index from all these ten countries, the time interval is from January 1, 2001, to September 31, 2009, and the data comes from Yahoo Finance (as a part of the data in MIBTEL and SMSI are lost, so only data of the abovementioned intervals are chosen here). These representative index are S\&P 500, Dow Jones, NASDAQ, NYSE index in America, Nikkei 225 in Japan, SSE in China, Hangseng index of Hong Kong, China, DAX of German, CAC 40 in France, FTSE 100 in the Great Britain, MIBTEL in Italy, BVSP of Brazil, SMSI of Spain, and GSPTSE in Canada, 14 in all, including main stock markets in North America, Europe, and Asia. The computation equation of return rate is $r_{t}=$ $100 *\left(\ln P_{t}-\ln P_{t-1}\right)$. The statistical characteristics of the daily return rate of aggregative index number are as shown in Table 1.

From the J-B statistics in Table 1, it can be seen that return of all indexes is not normally distributed. Besides, through the ADF test of return series, the result shows that all the return series are stationary. The result from further ARCHLM test shows that the probability of all indexes in ARCHLM test is less than significance level of $1 \%$, which shows that there indeed exists significant $\mathrm{ARCH}$ effect in residual series, and therefore, the GARCH model can be introduced to characterize the heteroscedastic volatility of each index's return series.

With model (12), the sample data of the above-mentioned 14 index is estimated with maximum likelihood method (the tool adopted is the software Eviews 6.0), and the result is shown in Table 2.

Among the estimated results of the 14 samples, through the test of coefficient estimated result of time variation process of risk compensation coefficient, it can be seem that most of the estimated results of $\eta_{0}$ and $\eta_{1}$ are significant at significance level of $10 \%$, though the coefficient of some index is not significant at significance level of $10 \%$, and the corresponding $P$ value is relatively small.

Further examination finds that the estimated results of $\eta_{0}$ are all positive and most of them ( 9 samples) are significant at $10 \%$, which means that the fixed risk compensation the 
investors demanded for risk is positive. This is in accordance with traditional theory. It can be seen as risk compensation the investors demand from the market for fixed risk in a certain period. The estimated results of $\eta_{1}$ in BVSP are greater than zero and not significant, while other estimated results of $\eta_{1}$ are all smaller than zero and most of them are significant, which shows that the current risk compensation coefficient is smaller than prior period. Prior gains $\left(\varepsilon_{t-1}>0\right)$ will reduce the risk premium the investors require for each unit of risk; that is, the investors' current extent of risk aversion decreases, which verifies the existence of "house money effect" on stock market; it also means that prior losses $\left(\varepsilon_{t-1}<0\right)$ will lead investors to demand more compensation for each unit risk and the current extent of risk aversion increases.

Results of the above empirical tests show that the conclusion of Thaler and Johnson (1990) [1] is still applicable on market level. Risk compensation coefficient also shows characteristics of time variation, prior decision-making outcomes (gains and losses) will affect current risk attitude, and there exists house money effect on stock market. To be concrete, on stock market, prior gains will decrease current extent of risk aversion and investors become more risk seeking, and this supports the house money effect, while prior losses will increase current extent of risk aversion.

According to viewpoints of Thaler and Johnson [1], combined with analysis of prospect theory, this is because when investors get prior gains, this part of gains is an independent mental account in editing stage, is segregated from the mental account of initial asset, and is regarded as "house money," then investors will consider that the gains can offset subsequent possible losses, and in subsequent investing behaviors, the extent of their risk aversion decreases; that is, they become more risk seeking, while with prior losses, investors dislike losses and become more sensitive to subsequent possible losses, so the "painful" feelings intensify; therefore, they become more risk aversion. If we apply this viewpoint to the whole stock market, the circumstances will be like the following: if the share price increases in prior period and exceeds the psychological expectations of the investors, they will think that they gain and regard it as "house money" mental account, and then investors will consider that the obtained gains can offset the following possible losses, so they are willing to bear greater risk in the current situation; namely, they become more risk seeking. In this way, investors tend to continue to hold or purchase shares whose price greatly increases. Because of investors' incomplete rational factors, there appears a kind of expansion in demand on the whole market. Therefore, house money effect can be used to explain investors' "buying winners" on the stock market; on the contrary, if share price decreases in prior period and becomes lower than investors' psychological expectations, they will think that they lose, and then they will worry about more possible losses in subsequence, so their extent of risk aversion intensifies and is likely to sell the shares; thus the demand of the whole market decreases, and this explains the investors' "selling losers" on the stock market to a certain extent.

\section{Conclusion}

This paper puts forward a new value function which explains a phenomenon about the effects of prior outcomes on risky choice. In addition, the paper takes the behavior of the whole stock market as the research object, adopts aggregative index number of 14 representative stocks around the world as samples, establishes a TVRA-GARCH-M model to investigate the influence of prior gains and losses on current risk attitude on the market, and tests the relationship between prior outcomes and current risk attitude on market level through empirical evidences. Compared with the past researches based on psychological experiments, the research method in this paper overcomes the disadvantage of incomplete simulation of real scenes in psychological experiments. Furthermore, the amount of data in samples in this paper is large and easy to obtain, and the data is also not influenced by the private factors of investors, so the result is more convincible. The result of this empirical experiment shows that, on level of the whole market, under the influence of prior gains, the extent of risk aversion in most of the stock market will decrease, which proves the general existence of "house money effect" on stock market. What is more, the extent of risk aversion will increase comparatively under the circumstance of prior losses, which supports the viewpoint of Thaler and Johnson [1] and Barberis et al. [14]. The research in this paper simply supposes that there exists kind of linear relationship between prior outcomes and current risk compensation coefficient, and just points out that prior gains and losses will induce changes in current risk attitude through empirical evidence. As to the concrete numerical relationship between them, it needs further research. Meanwhile, further researches on internal mechanism of the time-varying risk attitude will also be of great theoretical and practical meanings.

\section{Conflict of Interests}

The authors declare that there is no conflict of interests regarding the publication of this paper.

\section{Acknowledgment}

This work was supported in part by the Natural Science Foundation of China (nos. 71171024, 71371195, an 71221061).

\section{References}

[1] R. H. Thaler and E. J. Johnson, "Gambling with the house money and trying to break even: the effect of prior outcomes on risky choice," Management Science, vol. 36, pp. 643-660, 1990.

[2] K. Keasey and P. Moon, "Gambling with the house money in capital expenditure decisions: an experimental analysis," Economics Letters, vol. 50, no. 1, pp. 105-110, 1996.

[3] P. Sadorsky, "Time-varying risk premiums in petroleum futures prices," Energy Economics, vol. 24, no. 6, pp. 539-556, 2002.

[4] D. Dillenberger and K. Rozen, "History-dependent risk attitude," Working Paper, University of Pennsylvania and Yale University, 2011. 
[5] D. Duxbury, R. Hudson, K. Keasey, Z. Yang, and S. Yao, "How prior realized outcomes affect portfolio decisions," Review of Quantitative Finance and Accounting, vol. 41, no. 4, pp. 611-629, 2013.

[6] Y. C. Huang and S. H. Chan, "The house money and breakeven effects for different types of traders: evidence from Taiwan futures markets," Pacific-Basin Finance Journal, vol. 26, pp. 1-13, 2014.

[7] R. Gertner, "Game shows and economic behavior: risk-taking on "Card Sharks"', The Quarterly Journal of Economics, vol. 108, pp. 507-521, 1993.

[8] R. H. Thaler, A. Tversky, D. Kahneman, and A. Schwartz, "The effect of myopia and loss aversion on risk taking: an experimental test," The Quarterly Journal of Economics, vol. 112, no. 2, pp. 646-661, 1997.

[9] M. Weber and H. Zuchel, "How do prior outcomes affect risk attitude? Comparing escalation of commitment and the housemoney effect," Decision Analysis, vol. 2, no. 1, pp. 30-43, 2005.

[10] L. F. Ackert, N. Charupat, B. K. Church, and R. Deaves, "An experimental examination of the house money effect in a multiperiod setting," Experimental Economics, vol. 9, no. 1, pp. 5-16, 2006.

[11] L. R. Martínez, C. Jaramillo, N. D. Roux, and J. C. Cárdenas, "It's not my money: an experiment on risk aversion and the house-money effect," Working Paper, Centro de Estudios Sobre Desarrollo Económico, 2010.

[12] P. W. Linville and G. W. Fischer, "Preferences for separating or combining events," Journal of Personality and Social Psychology, vol. 60, no. 1, pp. 5-23, 1991.

[13] K. Sullivan and T. Kida, "The effect of multiple reference points and prior gains and losses on managers' risky decision making," Organizational Behavior and Human Decision Processes, vol. 64, no. 1, pp. 76-83, 1995.

[14] N. Barberis, M. Huang, and T. Santos, "Prospect theory and asset prices," The Quarterly Journal of Economics, vol. 116, no. 1, pp. 1-53, 2001.

[15] N. Barberis and W. Xiong, "What drives the disposition effect? An analysis of a long-standing preference-based explanation," Journal of Finance, vol. 64, no. 2, pp. 751-784, 2009.

[16] H. Shefrin and M. Statman, "The disposition to sell winners too early and ride losers too long: theory and eridence," Journal of Finance, vol. 40, no. 3, pp. 777-790, 1985.

[17] T. Odean, "Are investors reluctant to realize their losses?" Journal of Finance, vol. 53, no. 5, pp. 1775-1798, 1998.

[18] D. Hirshleifer, "Investor psychology and asset pricing," Journal of Finance, vol. 56, no. 4, pp. 1533-1597, 2001.

[19] P. Brown, N. Chappel, R. S. Rosa, and T. Walter, "The reach of the disposition effect: large sample evidence across investor classes," International Review of Finance, vol. 6, no. 1-2, pp. 43-78, 2006.

[20] Y. L. Hsu and E. H. Chow, "House money and investment risk taking," in Proceedings of the 23rd Australasian Finance and Banking Conference, 2010.

[21] A. Frino, J. Grant, and D. Johnstone, "The house money effect and local traders on the Sydney Futures Exchange," Pacific Basin Finance Journal, vol. 16, no. 1-2, pp. 8-25, 2008.

[22] Y.-J. Liu, C.-L. Tsai, M.-C. Wang, and N. Zhu, "Prior consequences and subsequent risk taking: new field evidence from the Taiwan futures exchange," Management Science, vol. 56, no. 4, pp. 606-620, 2010.

[23] Y. L. Hsu and E. H. Chow, "The house money effect on investment risk taking: evidence from Taiwan," Pacific-Basin Finance Journal, vol. 21, no. 1, pp. 1102-1115, 2013.
[24] A. Tversky and D. Kahneman, "Advances in prospect theory: cumulative representation of uncertainty," Journal of Risk and Uncertainty, vol. 5, no. 4, pp. 297-323, 1992.

[25] K. J. Arrow, Essays in the Theory of Risk Bearing, Markham, Chicago, Ill, USA, 1971.

[26] J. W. Pratt, "Risk aversion in the small and in the large," Econometrica, vol. 32, no. 1-2, pp. 122-136, 1964.

[27] J. E. Stiglitz, "The effects of income, wealth, and capital gains taxation on risk-taking," The Quarterly Journal of Economics, vol. 3, pp. 63-283, 1969.

[28] R. Raskin and M. J. Cochran, "Interpretations and transformations of scale for the Pratt-Arrow absolute risk aversion coefficient: implications for generalized stochastic dominance," Western Journal of Agricultural Economics, vol. 11, no. 2, pp. 204210, 1986.

[29] J. M. E. Pennings and B. Wansink, "Channel contract behavior: the role of risk attitudes, risk perceptions, and channel members' market structures," Journal of Business, vol. 77, no. 4, pp. 697-723, 2004

[30] D. Kahneman and A. Tversky, "Prospect theory: an analysis of decision under risk," Econometrics, vol. 47, pp. 263-291, 1979.

[31] A. Tversky and D. Kahneman, "The framing of decisions and the psychology of choice," Science, vol. 211, no. 4481, pp. 453$458,1981$.

[32] K. M. M. Ericson and A. Fuster, "Expectations as endowments: evidence on reference-dependent preferences from exchange and valuation experiments," The Quarterly Journal of Economics, vol. 126, no. 4, pp. 1879-1907, 2011.

[33] D. Gill and V. Prowse, "A structural analysis of disappointment aversion in a real effort competition," American Economic Review, vol. 102, no. 1, pp. 469-503, 2012.

[34] B. Köszegi and M. Rabin, "A model of reference-dependent preferences," The Quarterly Journal of Economics, vol. 121, no. 4, pp. 1133-1165, 2006.

[35] B. Köszegi and M. Rabin, "Reference-dependent risk attitudes," American Economic Review, vol. 97, no. 4, pp. 1047-1073, 2007.

[36] B. Köszegi and M. Rabin, "Reference-dependent consumption plans," American Economic Review, vol. 99, no. 3, pp. 909-936, 2009.

[37] T. Strzalecki, "Axiomatic foundations of multiplier preferences," Econometrica, vol. 79, no. 1, pp. 47-73, 2011.

[38] F. Wen and X. Yang, "Skewness of return distribution and coefficient of risk premium," Journal of Systems Science and Complexity, vol. 22, no. 3, pp. 360-371, 2009.

[39] H. M. Anderson, K. Nam, and F. Vahid, "An asymmetric nonlinear smooth transition GARCH models," in Nonlinear Time Series Analysis of Economic and Finnacial Data, P. Rothman, Ed., vol. 1, pp. 191-207, Kluwer Academic, Boston, Mass, USA, 1999.

[40] G. Li, “Time-varying risk aversion and asset prices," Journal of Banking \& Finance, vol. 31, no. 1, pp. 243-257, 2007.

[41] J. Cotter and J. Hanly, "Time-varying risk aversion: an application to energy hedging," Energy Economics, vol. 32, no. 2, pp. 432-441, 2010. 


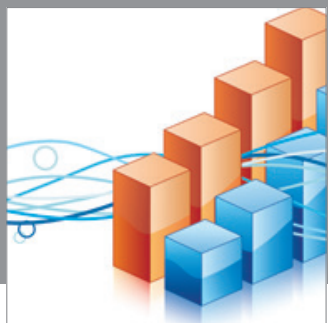

Advances in

Operations Research

mansans

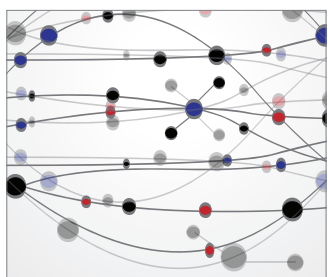

The Scientific World Journal
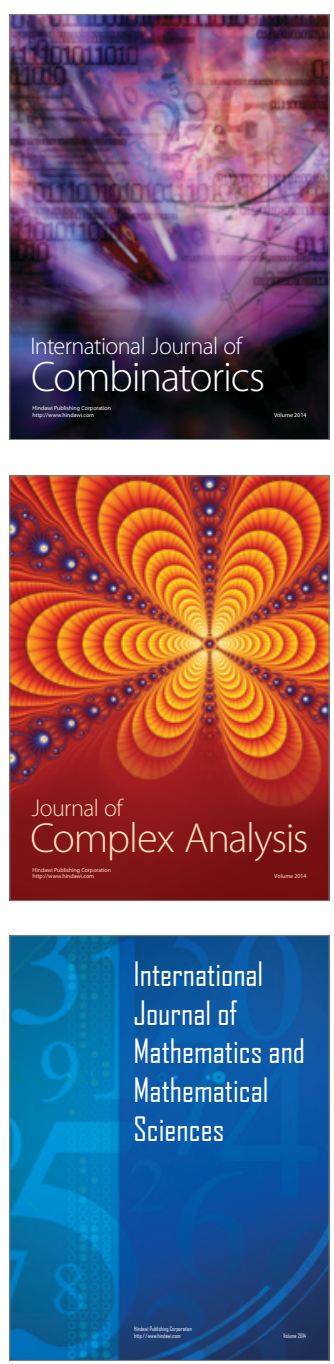
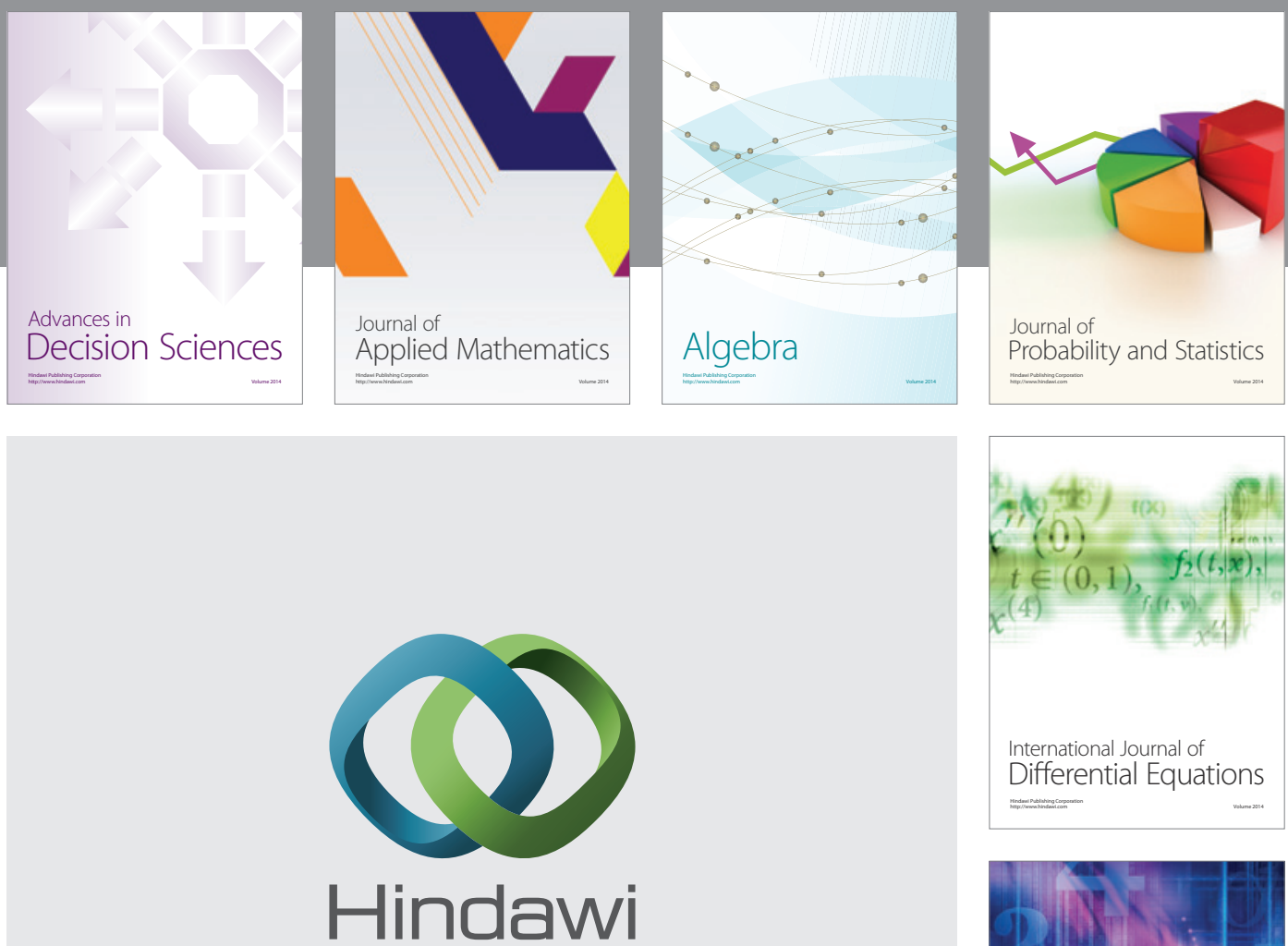

Submit your manuscripts at http://www.hindawi.com
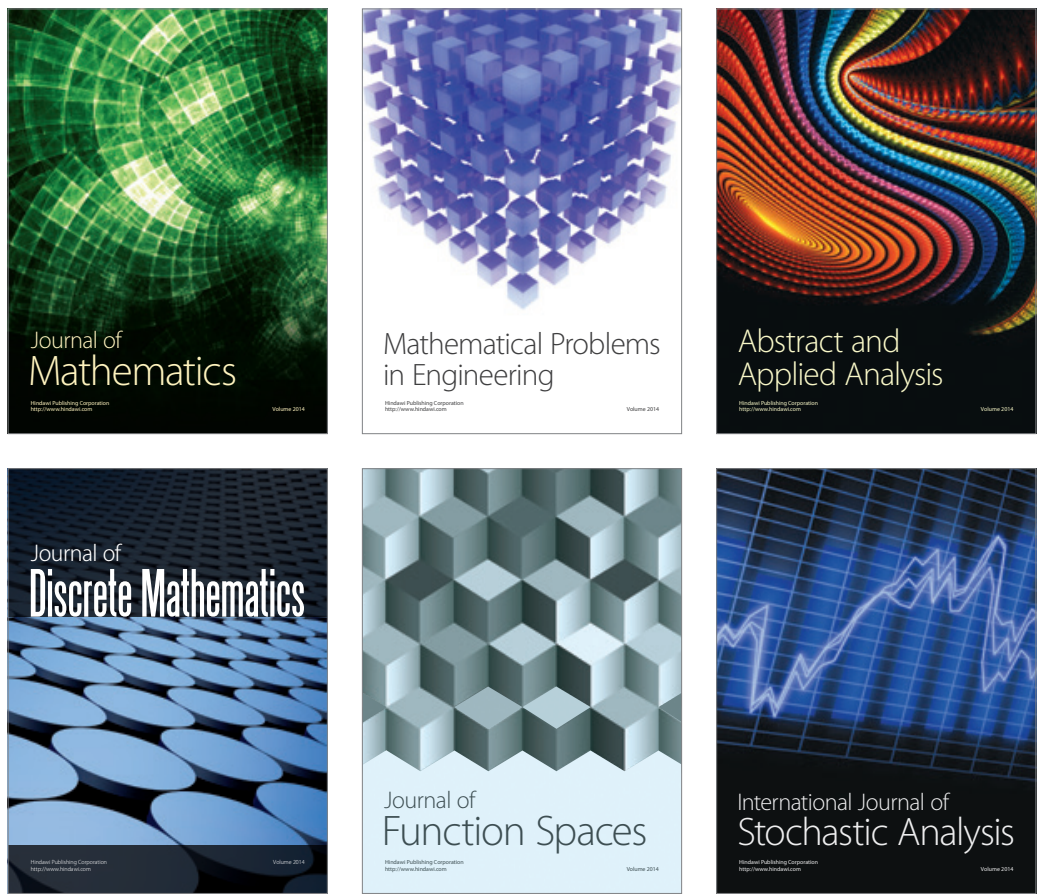

Journal of

Function Spaces

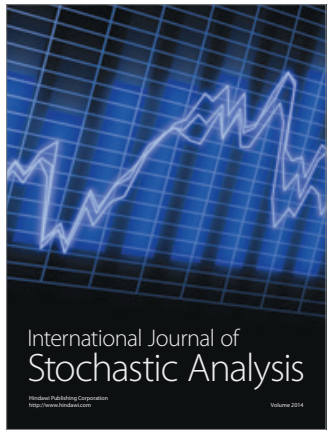

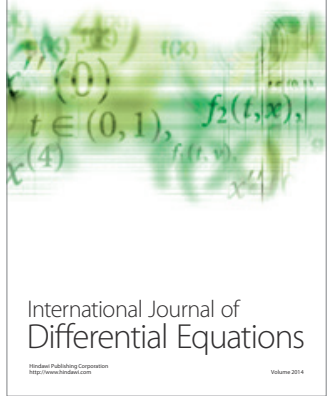
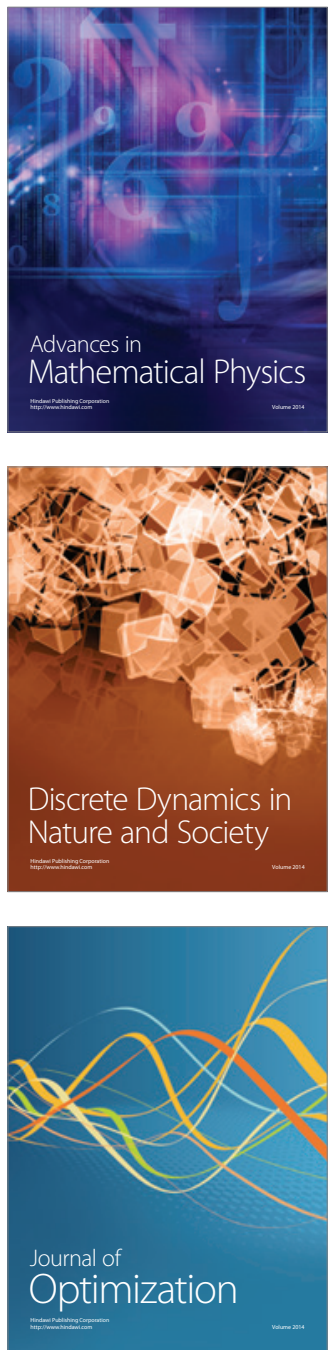